\title{
Evaluation of Problem-Based Learning (PBL) Implementation: Perception of Students from Two Medical Schools
}

\author{
Hani S. Atwa ${ }^{1,2^{*}}$ and Nahla Hassan ${ }^{1}$ \\ ${ }^{1}$ Department of Medical Education, Faculty of Medicine, Suez Canal University, Egypt, and ${ }^{2}$ Ibn Sina National \\ College for Medical Studies, Jeddah, Saudi Arabia
}

\begin{abstract}
Background: Institutions may have different interpretations of Problem-Based Learning (PBL) characteristics. As a result, the implementation of PBL may be completely different from one institution to another. Aim: This study aims to evaluate and compare the implementation of PBL at the Faculty of Medicine, Suez Canal University (FOM-SCU), Egypt and Ibn Sina National College for Medical Studies (ISNC), Saudi Arabia from the viewpoint of student at both schools. Methods: This is a descriptive study, conducted at the FOM-SCU and ISNC and a convenience sample was taken from students in both schools ( 381 students at FOM-SCU and 479 students at ISNC). A validated, self-administered questionnaire was used to evaluate the quality of PBL implementation from the students' points of view. Validity and reliability studies have been done for the questionnaire after its translation into Arabic. Descriptive statistics together with regression analysis were applied, using SPSS v.20. Results: Overall students' satisfaction with the current implementation of PBL gave mean scores of $3.44 \pm 0.70$ and $3.59 \pm 0.63$ at ISNC and FOM$\mathrm{SCU}$, respectively. Scores were consistently higher for FOM-SCU students over all the evaluated subscales. Statistically significant differences $(p<0.05)$ in student-centered learning, selfdirected learning and the quality of the small groups have been found between both schools, consistently higher in FOM-SCU. Conclusion: The current study found that students are moderately satisfied by the quality of PBL at their respective schools. However, moderate scores indicate that there is room for more improvement in the implementation of PBL at both schools, especially in the training of PBL facilitators. Students at FOM-SCU were more satisfied by PBL at their schools than students of ISNC, especially regarding student-centered learning, selfdirected learning and the quality of the small groups.
\end{abstract}

Keywords: Problem-Based Learning (PBL), PBL Implementation, FOM-SCU, ISNC

\section{Introduction}

Problem-based learning (PBL) has been utilized for over 40 years in a variety of different disciplines and has had a major impact on thinking and practice in medical education $^{(1)}$. Institutions may interpret PBL characteristics differently. Hence, the implementation of PBL may be completely different from one institution to anoth$\mathrm{er}^{(2)}$. Different studies investigated the remote effects of PBL on the outcomes of student education by using graduate survey data ${ }^{(1,2)}$. There is no reported evidence whether the implementation of PBL differs according to the culture and the model adopted or not. This study aims to 
evaluate and compare the quality of PBL implementation at the Faculty of Medicine, Suez Canal University (FOM-SCU) in Egypt and Ibn Sina National College for Medical Studies (ISNC) in Saudi Arabia from the viewpoint of students at both schools in terms of student-centered learning, small groups size and dynamics, educational problems, facilitators (tutors) and students' involvement in self-directed learning. The development of curriculum of FOM-SCU has taken into consideration the new trends in medical education such as PBL, community-based education $(\mathrm{CBE})$, and student-centered learning. FOM-SCU implements pure PBL as the main educational strategy, especially at the preclinical phase (first three years of the curriculum). ISNC encompasses four health professions education programs (Medicine, Dentistry, Clinical Pharmacy and Nursing). The Medicine program runs an integrated curriculum that has both systems-based modules and PBL. The PBL at ISNC is implemented in a hybrid manner, as other teaching methods, like interactive lectures, are implemented side by side to PBL. Pure PBL means that the main educational strategy is $\mathrm{PBL}$, and the entire curriculum is implemented through PBL small group sessions. However, in hybrid PBL curriculum student learning is supported by lectures and tutorial sessions ${ }^{(3)}$. Choice of those two medical schools was based on the similarity of the cultural context, being in two Arab countries with similar cultural back-grounds. In addition, FOM-SCU is the only medical school that runs a pure PBL curriculum in Egypt, while ISNC is the first medical school that incorporates PBL in its curriculum. in a hybrid manner in Saudi Arabia. Moreover, choosing one pure PBL school (FOM-SCU) and another hybrid PBL school (ISNC) is supposed to help detect the difference in implementation of PBL in such two cases.

\section{Patients and Methods}

Study context and population: This is a descriptive study, conducted at the FOMSCU and ISNC. The study included students of the $2^{\text {nd }}$ and $3^{\text {rd }}$ years at FOM-SCU (381 students), where PBL is the only educational strategy. At ISNC, the study included students of the $3^{\text {rd }}$ and $4^{\text {th }}$ years (479 students), where PBL is one of the main educational strategies. Choice of those years at both schools was based on the fact that the main bulk of PBL implementation takes place in those curriculum years. A convenience sample was taken, including all the students in the mentioned study years. The research protocol was approved by the Curriculum Committees and Research Ethics Committees at both schools.

Instrument: A validated, self-administered PBL implementation questionnaire was used to evaluate the implementation of PBL from the students' points of view. The questionnaire has been tested for validity and reliability by Patria ${ }^{(2)}$ and proved to be valid and reliable for evaluating the implementation of PBL in medical schools. The questionnaire included six subscales, which are: Student-Centered Learning, Small Group, Problem as a Stimulus, Realworld Problem, Teacher as Facilitator and Self-directed Learning. Each subscale is represented through several items. Each item is judged by the students based on a 5-point Likert scale, where 1= Never, 2= Rarely, 3= Sometimes, 4= Usually and 5= Always. The questionnaire was translated by experts in medical education into Arabic, to make it easily understandable for the students whose mother tongue is Arabic. After translation, the questionnaire was introduced firstly on a pilot basis to confirm its reliability and validity. Cronbach's alpha was performed to assess its internal consistency. Validity of the ques- 
tionnaire was established through confirmatory factor analysis. In addition, face validity was established by revision of the translated questionnaire by experts from the Medical Education Unit at ISNC. The questionnaire was administered anonymously to the students and they were given the liberty not to participate in the study without any consequences.

\section{Statistical analysis}

Data was collected and entered to Microsoft Excel 2010. Mean scores of the six sub-scales were compared across both schools. Overall mean scores for perception of the quality of PBL implementation were correlated with the study years at both schools using linear regression analysis. For statistical analysis, IBM SPSS v.20(4) was used. The calculated probability of less than $5 \%(p<0.05)$ was taken as the cut-off point for statistical significance.

\section{Results}

The overall response rate was $81 \%$ of the total of 381 students at FOM-SCU $(n=309)$ and $73 \%$ of the total of 479 students at ISNC $(n=350)$. Internal consistency was established through Cronbach's alpha test. Table 1 shows high values for internal consistency for each of the components (subscales) of the questionnaire, as well as for the questionnaire as a whole. Alpha values ranged from 0.725 (for Studentcentered Learning) to 0.879 (for Teacher as Facilitator) (Table 1). Validation of the questionnaire was established through factor analysis (Table 2), which showed heavy loading on one factor for all the subscales of the questionnaire. Gender and study year did not load on the same factor with the components of the questionnaire or with each other. Table 3 shows differences between the mean scores at both schools. The differences are to the side of FOM-SCU for most of the items.

Table 1: Internal consistency study of the translated questionnaire using Cronbach's alpha

\begin{tabular}{|l|c|}
\hline Components & Cronbach's alpha \\
\hline Student-centered Learning & 0.725 \\
\hline Small Group & 0.832 \\
\hline Problem as Stimulus & 0.859 \\
\hline Real World Problems & 0.771 \\
\hline Teacher as Facilitator & 0.879 \\
\hline Self-directed Learning & 0.867 \\
\hline All Components Together & 0.824 \\
\hline
\end{tabular}

However, nearly half of the differences were statistically significant. Regarding the six main components (subscales) of the questionnaire, only three of them (Student-centered Learning, Small Group, and Self-directed Learning) showed statistically significant differences that were to the side of FOM-SCU. The overall score for the whole questionnaire showed also a statistically significant difference in the mean score; again, to the side of FOMSCU. The relationship between study years and overall perception mean score was studied through a linear regression analysis (Table 4). At ISNC, it was found that progression in the study years (from Year 3 to Year 4) was associated with a decrease in the overall mean score for student perception of the quality of the PBL implementation (negative values for $B$ and $t)$. This inversed relationship was statistically significant $(p=0.000)$. However, at FOM-SCU progression in the study years (from Year 2 to Year 3) was associated with an increase in the overall mean perception score. This relationship was statistically significant $(p=0.000)$.

\section{Discussion}

In the current study, although we used a previously validated questionnaire, revalidation of the questionnaire was established through factor analysis, because of 
the different context and language. Factor analysis showed heavy loading on one factor for all the subscales of the questionnaire.

Table 2: Validation of the translated questionnaire through confirmatory factor analysis

\begin{tabular}{|c|c|c|c|}
\hline \multirow[b]{2}{*}{ Components } & \multicolumn{3}{|c|}{ Factor Loading } \\
\hline & 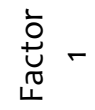 & 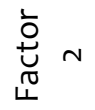 & 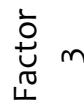 \\
\hline $\begin{array}{l}\text { Student-centered } \\
\text { Learning }\end{array}$ & 0.68 & - & - \\
\hline Small Group & 0.64 & - & - \\
\hline Problem as Stimulus & 0.85 & - & - \\
\hline Real World Problems & 0.77 & - & - \\
\hline Teacher as Facilitator & 0.69 & - & - \\
\hline Self-directed Learning & 0.77 & - & - \\
\hline Gender & - & 0.89 & - \\
\hline Study Year & - & - & 0.95 \\
\hline
\end{tabular}

This inferred validity of the translated tool was similar to the results of Patria ${ }^{(2)}$ who confirmed the validity of the original tool through confirmatory factor analysis. In addition, good internal consistency indices (Cronbach's alpha) indicated that the PBL implementation questionnaire was reliable, making it suitable for evaluation purposes. Generally, the study results indicate that students are moderately satisfied by the quality of PBL at their respective schools. Shamsan and Syed ${ }^{(5)}$ stated that their students are satisfied with the quality of PBL implementation. Also, Loyens et al. ${ }^{(6)}$ and Yuan et al. ${ }^{(7)}$ concluded that their students considered PBL as effective in gaining professional knowledge, in addition to the skills of problem-solving, selfdirected learning and group work. In the three main subscales representing self-learning and group dynamics (which are: Student-centered Learning, Self-directed Learning and Small Group), we found statistically significant differences between both schools (all to the side of FOM-SCU). These differences may be attributed to the fact that PBL curriculum at FOM-SCU is the sole educational strategy (pure PBL) from the first day at medical school, whereas at ISNC PBL is a hybrid strategy that starts from the second year of medical studies (after a general preparatory year). This interpretation is supported by $\mathrm{Hung}^{(8)}$ who found that pure PBL is superior to hybrid PBL in the ability to help students' selflearning. Moreover, Tsou et $a^{(9)}$ found that the PBL curriculum encouraged students to improve their self-directed learning abilities. Regarding the suitability of group size to stimulate group discussion, a statistically significant difference was found in student perception for the favor of FOM-SCU, where students of FOM-SCU perceived the group size (8-10 students/group) to better stimulate discussions than students of ISNC (13-17 students/group).

Table 3: Comparison between mean scores $( \pm S D)$ at both schools

\begin{tabular}{|l|c|c|c|c|}
\hline Item & $\begin{array}{c}\text { ISNC } \\
(\mathrm{n}=350)\end{array}$ & $\begin{array}{c}\text { FOM-SCU } \\
(\mathrm{n}=309)\end{array}$ & t-test & $\begin{array}{c}p \text { - } \\
\text { value }\end{array}$ \\
\hline Student-centered Learning: & $3.52 \pm 0.97$ & $3.77 \pm 0.85$ & 3.53 & $0.001^{*}$ \\
\hline $\begin{array}{l}\text { Students are responsible for their own learn- } \\
\text { ing }\end{array}$ & $3.84 \pm 1.03$ & $3.91 \pm 0.95$ & 0.91 & 0.365 \\
\hline $\begin{array}{l}\text { Students are actively involved in learning } \\
\text { process }\end{array}$ & $3.36 \pm 1.13$ & $3.90 \pm 1.15$ & 6.06 & $0.000^{*}$ \\
\hline - Students have autonomy in learning process & $3.38 \pm 1.19$ & $3.49 \pm 1.26$ & 1.15 & 0.252 \\
\hline$\quad \begin{array}{l}\text { Small Group: } \\
\text { The group size is appropriate to stimulate } \\
\text { group discussion }\end{array}$ & $3.51 \pm 0.97$ & $3.70 \pm 1.11$ & 2.33 & $0.020^{*}$ \\
\hline $\begin{array}{l}\text { The learning groups have a positive atmos- } \\
\text { phere (i.e. non-threatening) }\end{array}$ & $3.56 \pm 1.02$ & $3.64 \pm 1.17$ & 0.93 & 0.353 \\
\hline $\begin{array}{l}\text { The group size is appropriate to encourage } \\
\text { active student participation }\end{array}$ & $3.67 \pm 1.20$ & $3.71 \pm 1.27$ & 0.41 & 0.679 \\
\hline
\end{tabular}




\begin{tabular}{|c|c|c|c|c|c|}
\hline \multicolumn{6}{|c|}{ Table 3 Cont. } \\
\hline & Problem as Stimulus: & $3.56 \pm 0.85$ & $3.58 \pm 0.82$ & 0.31 & 0.759 \\
\hline - & problems match students' knowledge level & $3.35 \pm 1.14$ & $3.49 \pm 0.95$ & 1.72 & 0.086 \\
\hline - & $\begin{array}{l}\text { The problems stimulate thinking, analysis, } \\
\text { and reasoning }\end{array}$ & $3.61 \pm 1.10$ & $3.63 \pm 1.00$ & 0.24 & 0.807 \\
\hline - & The problems ensure self-directed learning & $3.77 \pm 1.11$ & $3.69 \pm 1.06$ & 0.95 & 0.345 \\
\hline & $\begin{array}{l}\text { The problems activate students' prior } \\
\text { knowledge }\end{array}$ & $3.57 \pm 1.07$ & $3.49 \pm 0.97$ & 1.01 & 0.315 \\
\hline - & $\begin{array}{l}\text { The problems lead to the discovery of the } \\
\text { learning objectives }\end{array}$ & $3 \cdot 53 \pm 1.11$ & $3.61 \pm 1.11$ & 0.92 & 0.356 \\
\hline - & The problems arouse students' curiosity & $3.50 \pm 1.19$ & $3.58 \pm 1.06$ & 0.91 & 0.362 \\
\hline & Real-world Problems: & $3.68 \pm 0.88$ & $3.75 \pm 0.81$ & 1.06 & 0.288 \\
\hline - & The problems are realistic & $3.78 \pm 1.27$ & $3.91 \pm 1.08$ & 1.42 & 0.156 \\
\hline - & The problems are clinically relevant & $3.82 \pm 1.03$ & $3.53 \pm 1.14$ & 3.41 & $0.000 *$ \\
\hline - & $\begin{array}{l}\text { The problems are related to a public health } \\
\text { topic }\end{array}$ & $3.65 \pm 1.03$ & $3.83 \pm 1.05$ & 2.22 & $0.027 *$ \\
\hline & $\begin{array}{l}\text { The problems generate multiple hypotheses } \\
\text { about their cause and solution }\end{array}$ & $3.45 \pm 1.06$ & $3.73 \pm 1.01$ & 3.47 & $0.000 *$ \\
\hline & Teacher as Facilitator: & $3.14 \pm 0.79$ & $3.22 \pm 0.87$ & 1.23 & 0.219 \\
\hline- & $\begin{array}{l}\text { The tutors have a clear picture about their } \\
\text { strengths or weaknesses as tutors }\end{array}$ & $3.11 \pm 0.95$ & $3.12 \pm 1.12$ & 0.12 & 0.902 \\
\hline & $\begin{array}{l}\text { The tutors are clearly motivated to fulfill } \\
\text { their role as a tutor }\end{array}$ & $2.99 \pm 1.00$ & $3.03 \pm 1.07$ & 0.49 & 0.622 \\
\hline & $\begin{array}{l}\text { The tutors stimulate the students to sum- } \\
\text { marize what they had learnt in their own } \\
\text { words }\end{array}$ & $3.05 \pm 1.30$ & $3.25 \pm 1.09$ & 2.15 & $0.032 *$ \\
\hline & $\begin{array}{l}\text { The tutors stimulate the students to search } \\
\text { for links between issues discussed in tutori- } \\
\text { al groups }\end{array}$ & $3.41 \pm 1.06$ & $3.66 \pm 1.10$ & 2.96 & $0.003 *$ \\
\hline - & $\begin{array}{l}\text { The tutors stimulate the students to under- } \\
\text { stand underlying mechanisms or theories }\end{array}$ & $3.54 \pm 1.11$ & $3.26 \pm 1.12$ & 3.22 & $0.001 *$ \\
\hline - & $\begin{array}{l}\text { The tutors stimulate the students to apply } \\
\text { knowledge to other situations or problems }\end{array}$ & $3.16 \pm 1.12$ & $3.16 \pm 1.28$ & 0.00 & 1.000 \\
\hline & $\begin{array}{l}\text { The tutors stimulate the students to give } \\
\text { constructive feedback about group work }\end{array}$ & $2.79 \pm 1.33$ & $3.09 \pm 1.19$ & 3.06 & $0.002 *$ \\
\hline- & $\begin{array}{l}\text { The tutors stimulate the students to evalu- } \\
\text { ate group cooperation regularly }\end{array}$ & $3.10 \pm 1.11$ & $3.18 \pm 1.22$ & 0.88 & 0.381 \\
\hline & Self-directed Learning: & $3.23 \pm 0.95$ & $3.53 \pm 0.86$ & 4.25 & $0.000 *$ \\
\hline & $\begin{array}{l}\text { Students take initiative in diagnosing their } \\
\text { learning needs }\end{array}$ & $3.16 \pm 1.34$ & $3.35 \pm 1.15$ & 1.96 & 0.050 \\
\hline - & Students formulate their own learning goals & $3.28 \pm 1.22$ & $3.68 \pm 1.11$ & 4.41 & $0.000 *$ \\
\hline - & Students decide the resources for learning & $3.34 \pm 1.15$ & $3.86 \pm 1.11$ & $5 \cdot 90$ & $0.000 *$ \\
\hline & $\begin{array}{l}\text { Students choose appropriate learning } \\
\text { strategies }\end{array}$ & $3.32 \pm 1.14$ & $3.65 \pm 1.15$ & 3.69 & $0.000 *$ \\
\hline & $\begin{array}{l}\text { Students evaluate the accuracy and value of } \\
\text { resources }\end{array}$ & $3.10 \pm 1.15$ & $3 \cdot 34 \pm 1.11$ & 2.72 & $0.006^{*}$ \\
\hline & $\begin{array}{l}\text { Students self-monitor their learning pro- } \\
\text { gress }\end{array}$ & $3.15 \pm 1.31$ & $3.31 \pm 1.08$ & 1.72 & 0.086 \\
\hline - & Overall Score & $3.44 \pm 0.70$ & $3.59 \pm 0.63$ & 2.89 & $0.003^{*}$ \\
\hline
\end{tabular}

* Statistically Significant

This result was supported by the result of Shankar et al. ${ }^{(10)}$ in their study using a spe- cific group effectiveness tool designed by Singaram et al. ${ }^{(11)}$, which concluded that 
groups of convenient size (6-11 students/group) allow the students to interact with each other in discussions and sharing viewpoints, which finally stimulates more learning. Students at both schools satisfactorily perceived the quality of the educational problems and their functioning as stimuli for learning. However, the difference between both schools was not statistically significant, which may indicate the attention paid to the structure and design of the educational problems at both schools. Quality of teachers as facilitators was perceived lowest among all other subscales at both schools. This is in congruence with the result of Leary et $a^{(12)}$ and Al-Drees et al(13) who got similar low perception scores. They explained that by the lack of effective staff training. Similarly, in our study the reason may be ascribed to lack of sustained training of the tutors in both schools. At FOM$\mathrm{SCU}$, training of tutors is done as a oneday workshop twice a year (once at the beginning of the academic year and another near its middle) while at ISNC it is done only once at the beginning of the academic year. Lyberg-Ahlander et al $^{(14)}$ concluded that PBL tutors need continuous support and training. In addition, some of the tutors may have the tendency to turn the small group sessions into lectures $^{(12)}$. Moreover, this may be due to lack of the ability of some tutors to give effective feedback to the students, as was found by Baroffio et al(15). At ISNC, general perception of the quality of the PBL implementation decreased with progression from Year 3 to Year 4.

Table 4: Linear regression analysis of the relationship between years of study at both schools and the overall perception mean score of the quality of PBL implementation:

\begin{tabular}{|l|ccccccc|}
\hline \multirow{2}{*}{$\begin{array}{l}\text { Dependent } \\
\text { Variable (Score) }\end{array}$} & $\begin{array}{c}\text { Independent } \\
\text { Variable } \\
\text { (Study Years) }\end{array}$ & \multicolumn{2}{c}{$\begin{array}{c}\text { Unstandardized } \\
\text { Coefficients }\end{array}$} & B & Std. Err & F & $\begin{array}{c}p_{-} \\
\text {value }\end{array}$ \\
\cline { 2 - 8 } $\begin{array}{l}\text { Overall Perception } \\
\text { Mean Score }\end{array}$ & Study Yrs at ISNC & -0.26 & 0.06 & -4.12 & 16.72 & $0.000^{*}$ \\
\cline { 2 - 9 } & Study Yrs at FOM-SCU & 0.39 & 0.08 & 5.05 & 12.76 & $0.000^{*}$ \\
\hline
\end{tabular}

* Statistically Significant

This inversed linear relationship is statistically significant, and may be attributed to the fact that in Year 4 at ISNC there is more emphasis on hospital-based training than on PBL. On the other hand, at FOM$\mathrm{SCU}$ the perception increases from Year 2 to Year 3. This positive linear relationship is statistically significant, and may be attributed to the fact that PBL is the only educational strategy at FOM-SCU, especially in the pre-clinical basic sciences phase (with the peak of PBL implementation at Year 2 and Year 3). The limitation of this study is that it depended mainly on the questionnaire to collect data (quantitative) from students. In future studies, we intend to use other qualitative methods like focus groups and structured in- terviews to deeply probe students' perception. In addition, it would have been more beneficial to include other sources for data collection like administrative staff and PBL tutors.

\section{Conclusions}

The current study indicates that students are moderately satisfied by the quality of PBL at their respective schools. However, scores were not very high, indicating that there is room for more improvement in the implementation of $\mathrm{PBL}$ at both schools, especially in the training of PBL facilitators. Students studying in a pure PBL program (FOM-SCU) were more satisfied by PBL at their school than students 
from hybrid PBL (ISNC), especially regarding student-centered learning, self-directed learning and the quality of the small groups. We recommend continuous monitoring and evaluation of different components of the PBL process. Of special importance are the PBL facilitators, where more development is needed for them to help conduction of better PBL sessions.

Conflict of interest: No potential conflict of interest relevant to this article was reported.

Funding: No funding has been obtained for this study.

Acknowledgment: The authors would like to thank the administration of both FOMSCU and ISNC and the students who participated in the study.

\section{References}

1. Strobel J, van Barneveld A. When is PBL More Effective? A Meta-synthesis of Meta-Analyses Comparing PBL to Conventional Classrooms. The Interdisciplinary Journal of Problem-based Learning 2009;3(1):44-58.

2. Patria P. The validity and reliability of a problem-based learning implementation questionnaire. J Educ Eval Health Prof 2015; 12:22.

3. Masek A, Yamin S. Problem Based Learning model: a collection from the literature. Asian Soc Sci. 2010;6:148-56.

4. IBM SPSS Statistics for Windows, Version 20.0. Armonk, NY: IBM Corp. 2011.

5. Shamsan B, Syed A. Evaluation of Problem Based Learning Course at College of Medicine, Qassim University, Saudi Arabia. Int J Health Sci (Qassim) 2009;3(2): 249-58.

6. Loyens S, Magda J, Rikers R. SelfDirected Learning in Problem-Based Learning and its Relationships with Self-Regulated Learning. Educ Psychol Rev 2008;20:411-27.

7. Yuan HB, Williams BA, Yin L, Liu M, Fang JB, Pang D. Nursing students' views on the effectiveness of prob- lem-based learning. Nurse Educ Today 2011;31 (6):577-581.

8. Hung W. Theory to reality: a few issues in implementing problem-based learning. Education Tech Research Dev 2011; 59:529-52.

9. Tsou KI, Cho SL, Lin CS, et al. ShortTerm Outcomes of a Near-Full PBL Curriculum in a New Taiwan Medical School Kaohsiung. Kaohsiung J Med Sci 2009;25(5):282-93.

10. Shankar PR, Nandy A, Balasubramanium R, Chakravarty S. Small group effectiveness in a Caribbean medical school's problem-based learning sessions. J Educ Eval Health Prof 2014; 11:5.

11. Singaram VS, van der Vleuten $C P$, van Berkel H, Dolmans DH. Reliability and validity of a Tutorial Group Effectiveness Instrument. Med Teach 2010;32 (3): e133-37.

12. Leary $H$, Walker A, Shelton B, Fitt M. Exploring the Relationships between Tutor Background, Tutor Training, and Student Learning: A Problem-based Learning Meta-Analysis. The Interdisciplinary Journal Problem-based Learning 2013;7(1):40-66.

13. Al-Drees $A$, Khalil $M$, Irshad $M$, Abdulghani HM. Students' perception towards the problem based learning tutorial session in a system-based hybrid curriculum. Saudi Med J 2015;36 (3):341-48.

14. Lyberg-Åhlander V, Lundskog M, Hansson $\mathrm{K}$. Experiencing the role of PBL tutor. Clin Linguist Phon 2014;28 (12):36-46

15. Baroffio A, Nendaz M, Perrier, Nu V. Tutor Training, Evaluation Criteria and Teaching Environment Influence Students' Ratings of Tutor Feedback in Problem-Based Learning. Adv Health Sci Educ Theory Pract. 2007 12(4):42739. 
